\title{
Anal Fissür Tedavisinde Düşük Doz Botulinum Uygulaması ile Yüksek Doz Botulinum Uygulamasının Karşılaştırılması
}

\author{
Comparison of Low Dose Botulinum Application and High Dose \\ Botulinum Application in Anal Fissure Treatment
}

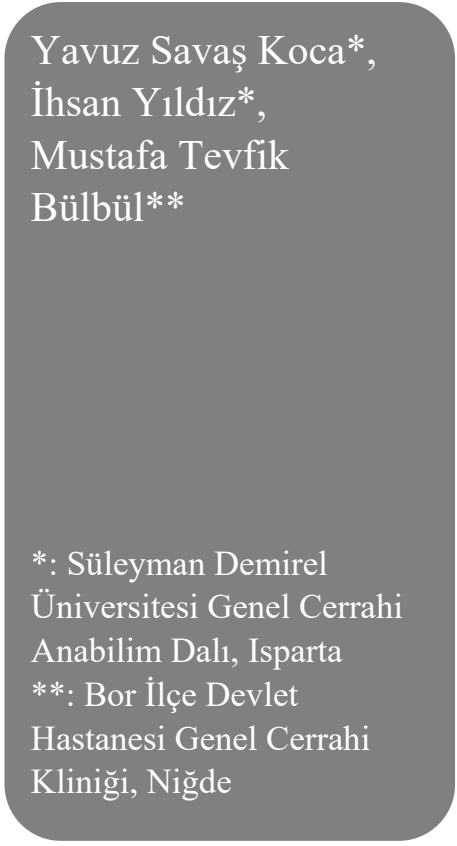

Yazışma Adresi:

Yard. Doç. Dr. Yavuz Savaş Koca

Süleyman Demirel

Üniversitesi Genel Cerrahi Anabilim Dalı, 32200

Isparta, Türkiye

E-mail:

yavuzsavaskoca@gmail.com Telefon: +90 5057172015 Fax: +902462234284
$\ddot{\mathbf{O z}}$

Amaç: Anal fissür tedavisinde kullanılan Botulinum toksininin kullanım dozlarının komplikasyon ve tedavi etkinliğinin araştırılması.

Gereç ve Yöntem: 2011-2013 yılları arasında anal fissürü tedavisi için Botulinum toksini injeksiyonu yapılan toplam 90 hastanın verileri geriye dönük olarak incelendi. Uygulama sonrası hastalar dermografik özellikleri ve erken (ağrı, hematom, infeksiyon, gaz inkontinansı, abse), geç komplikasyonları (gayta inkontinansı, nüks) bakımından incelendi.

Bulgular: Tedavide 30 İU Botulinum uygulanan 44 hastadan 34'ünde anal fissürün tamamen iyileştiği görüldü. İyileşme olmayan 10 hastaya 2 . kez Botulinum enjeksiyonu yapıldı. Semptomları ve fissürü gerilemeyen 4 hastaya ise aynı tedavi 3 . kez tekrarlandı. 4 hastanın sonraki kontrollerinde 1 hastada tamamen iyileşme izlendi. 3 hastada yeterli iyileşme saptanmadi. Bir y1llık kontrolde ise 3 hastada nüks anal fissür tespit edildi.

Tedavide 90 İU ile uygulanan 46 hastadan 40'1nda anal fissürün tamamen iyileştiği görüldü. İyileşme olmayan 6 hastanın ikisi kendi istekleri üzerine sfinkterotomi operasyonu ile tedavi edilirken diğer 4 hastada yeniden Botulinum enjeksiyonu yapıldı. $\mathrm{Bu} 4$ hastanın sonraki kontrollerinde tamamen iyileşme izlendi. Bir yıllık kontrolde ise 2 hastada nüks anal fissür tespit edildi.

Sonuçlar: Botulinum toksini enjeksiyonu düşük komplikasyon ve yaklaşık \%90'na varan etkinliği ile güvenli bir şekilde uygulanabilir. Yüksek doz uygulamada geçici komplikasyonlar daha fazla görülmekle birlikte tekrar uygulama gereksinimi düşük doz uygulamaya nazaran anlamlı şekilde düşüktür. $\mathrm{Bu}$ da hasta memnuniyeti ve maliyet açısından yüksek doz uygulamayı daha tercih edilebilir bir yöntem kılmaktadır.

Anahtar kelimeler: Anal Fissür, Botulinum Toksin, Doz, Nüks.

\begin{abstract}
Objective: To investigate complications and treatment effectiveness of botulinum toxin doses used in anal fissure treatment.

Materials and Methods: A total of 90 patients who underwent botulinum toxin injection for anal fissure treatment between 2011 and 2013 were
\end{abstract}


retrospectively investigated. The demographic characteristics of the patients and early (pain, hematoma, infection, gas incontinence, abscess), late complications (fecal incontinence, recurrence) were investigated after the application.

Results: 30 IU Fifty-four patients from 44 patients who were treated with botulinum had anal fissure completely cured. Botulinum injection was performed second time 10 patients who did not heal. The same treatment was repeated 3 times in 4 patients whose symptoms and fissure were not reduced. In the subsequent controls, complete recovery was observed in one but no improvement was observed in 3 patients. In one year control, recurrent anal fissure was observed in 3 patients.

In 40 of the 46 patients treated with $90 \mathrm{IU}$ of treatment, the anal fissure was completely healed. Two of the 6 patients who did not heal were treated with sphincterotomy operation on their own wishes, while the other 4 patients received botulinum injection again. Complete recovery was observed in subsequent controls of these 4 patients. In one year control, recurrent anal fissure was observed in 2 patients.

Conclusion: Botulinum toxin injection can be safely administered with low complication and up to about 90\% efficiency. Although transient complications are more common in high dose administration, the need for repeat administration is significantly lower than in low dose administration, which makes high dose administration a more preferable method in terms of patient satisfaction and cost.

Keywords: Anal Fissure, Botulinum Toxin, Dose, Recurrence

\section{Giriş}

Anal kanalın son kismından linea dentataya kadar uzanan yüzeysel yırtık anal fissür olarak tanımlanır. Genellikle dışkılama sırasında ağrı ve gaitaya bulaşık kırmızı renkli kanama şeklinde belirti verir (1-2).

Fissür oluşmasında çoğunlukla dışkılama sırasında zorlanma ve kabızlığa bağlı travma en iyi bilinen etiyolojik faktörlerdir. Ayrıca ishalli gaita, supozituar veya rektal enema uygulamaları, cerrahi girişimler de (stapler, anal dilatatör, ekartör vb.) anodermde yırtılmaya yol açabilirler (1).

Anal fissür genellikle posterior orta hatta, kadınlarda ise vajinal doğum sırasında anterior orta hatta görülür. Ayrıca crohn, tüberküloz, HIV, sifiliz, anal kanser gibi spesifik sebepler de atipik yerlerde fissürler oluşabilir (1). Akut gelişen fissürler zor muayene edilen ağrilı, yüzeysel bir yırtık şeklindedir. Kendiliğinden iyileşme olmazsa; fissür kenarları ödemli hale gelir, tabanında internal sfinkter adalesi lifleri görülür, anüs dışında nöbetçi meme olarak ödemli cilt pilisi ve fissür proksimalinde hipertrofik deri papillası görülür. Akut fissür spontan iyileşmezse kronik fissür ile suçlanır.
Bunun nedeni internal sfinkterdeki ağrilı spazmdır. Bunun sonucu anodermin kan akımı bozulur ve fissür fibrotik hale gelerek kronikleşir (1-2).

Tedavisinde tekrarlayan travmayı azaltmak için defekasyon kolaylaştırılmalıdır. İlk olarak posadan zengin gida ve siv1 tüketiminin arttırılması önerilir. Daha sonra internel sfinkterin ağrılı spazmını çözmek için düz kas gevşetici krem veya jel içeren ilaçlar fissür tedavisinde en sik kullanılan $\% 0.2$ nitroglycerin, \%0.4'lük isosorbid mononitrat, $\% 2$ 'lik diltiazem, \%2'lik nifedipin ve trimebutin krem gibi ilaçlar semptomatik iyileşme sağlar. Medikal tedavi ve diyet ile iyileşme sağlanamaması durumunda cerrahi tedavi uygulanır (1). Kontrollü anal dilatasyon, subkutan fissürotomi, mukozal veya dermal flep ile fissür tabanının kaplanması ve açık veya kapalı lateral internal sfinkterotomi yapılabilir. Sfinkterotomiden sonra anal fissürde çok yüksek iyileşme oranları yakalanmakla birlikte \%2-3 dişk1 inkontinansı oluşabilir $(3,4)$. Bu nedenle alternatif tedavi yolları arayışı ve sfinkteri geçici olarak gevşetecek botulinum toksini gibi maddeler gündeme gelmiştir. Botulinum toksini toplam 
injeksiyon dozu genellikle 5-200 ünite civarındadır ancak doz ve uygulama yeri konusunda değişik görüşler vardır $(5,6)$. Plaseboya göre üstün ancak lateral internal sfinkterotomiye göre daha kötü olduğu bildirilmektedir $(7,8)$. Düșük dozlarda bile geçici inkontinas bildirilmektedir (3-6). Botulinum toksini anal fissür tedavisinde pek çok çalışma olmasına karşın gerçekten yüksek dozda kullanımı ile ilgili literatürde çok yazı bulunmamaktadır $\quad(9,10)$. Yapılan birçok yayında internal sfinktere 3 faklı noktadan farklı dozlarda (15 IU- 150 IU) enjeksiyonlar tanımlanmıștır (3). Ancak hala uygulama dozu konusu tartışmalı bir konudur.

\section{Gereç ve Yöntem}

Bu çalışma için Süleyman Demirel Üniverstesi Tıp Fakültesi Klinik Araştırmalar Etik Kurulundan 21.12.2016 tarihinde 190 say1 numarasıyla etik kurul onayı alınmıştır. 20112013 yılları arasında özel bir hastanede anal fissür tedavisi için botulinum toksini injeksiyonu yapılan toplam 90 hastanın verileri geriye dönük olarak incelendi. Bir seansta verilen toplam doza göre 2 grup oluşturuldu. 30 IU uygulanan grup düşük doz (Grup I), 90 IU uygulanan grup yüksek doz grubu (Grup II) olarak adlandırıldı. Uygulama sonrası hastalar dermografik özellikleri ve erken (ağr1, hematom, infeksiyon, gaz inkontinans1, abse), geç komplikasyonları (gayta inkontinansı, nüks) bakımından incelendi. Birden fazla anal fissürü olan, yandaş hastalığ olan (hemoroid, crohn, tüberküloz, sfiliz, aids, malignite vs), daha önce anal cerrahi geçirmiş olan ve 1. yıl kontrollünde ulaşılamayan tüm hastalar çalışma dișı birakıldı.

Botulinum toksini uygulamaları ameliyathane şartlarında yapıldı. Her birinde 100 IU botulinum toksini içeren flakonlar (Botox 100 IU liyofilize toz içeren flakon, Allergen Pharmaceuticals Ireland) bir mililitre 0,1 ml'sinde 10 IU botulinum toksini serum fizyolojik ile sulandırıldı. Düşük doz grubuna toplam $30 \mathrm{IU}$ botulinum toksini herhangi bir anestezi uygulanmadan önce anoderm \%10'luk povidone iodine solüsyonu temizlenip litotomi pozisyonunda internal sfinktere üç değişik noktadan (sağ, sol, posterior) her bir noktaya 10 IU olacak şekilde uyguland. Yüksek doz grubuna toplam 90 IU botulinum toksini herhangi bir anestezi uygulanmadan önce anoderm \%10'luk povidone iodine solüsyonu temizlenip litotomi pozisyonunda internal sfinktere üç değişik noktadan (sağ, sol, posterior) her bir noktaya 30 IU olacak şekilde uyguland1. Tüm hastalar injeksiyondan sonra ertesi gün, 1 . hafta ve 1 . ay muayene edildi. 1 yıl sonrada telefonla ulaşılıp yakınmalarının ve nükslerinin olup olmadığı sorguland1.

İstatiksel analizde, SPSS ${ }^{\circledR}$ (version 21,0 for Windows $\AA$, SPSS inc $\AA$, Chicago, IL, USA) programı kullanıldı. Sonuçlar mutlak frekans (n), persentil (\%) ve ortalama \pm standart sapma (SD) olarak ifade edilmiştir. Dermografik özellikler $\mathrm{Ki}$ Kare testi ile değerlendirildi. $\mathrm{p}<0,05$ değeri anlamlı kabul edildi.

\section{Bulgular}

Her iki grupta yaş ortalaması cinsiyet ve yakınmalar açısından istatiksel olarak anlamlı fark saptanmadı (Tablo 1).

Tedavide 30 IU Botulinum uygulanan 44 hastadan 34 hastada fissürün tamamen iyileştiği görüldü. İyileşme olmayan 10 hastaya 2 . kez Botulinum enjeksiyonu yapıld1. Semptomları ve fissürü gerilemeyen 4 hastaya ise aynı tedavi 3. kez tekrarlandı. 4 hastanın sonraki kontrollerinde 1 hastada tamamen iyileşme izlendi. 3 hastada yeterli iyileșme izlenmedi. Bir y1llık kontrolde ise 3 hastada nüks anal fissür tespit edildi. Bu grupta ișlem sonrası 23 hastada perianal ağrı şikâyeti oldu. Başka komplikasyon izlenmedi.

Tedavide 90 İU ile uygulanan 46 hastadan 40 hastada fissürün tamamen iyileştiği görüldü. İyileşme olmayan 6 hastanın ikisi kendi 
Tablo 1. Bulgular

\begin{tabular}{|c|c|c|c|}
\hline & 30 IU enjeksiyon & 90 IU enjeksiyon & p değeri \\
\hline \multicolumn{4}{|l|}{ Cinsiyet } \\
\hline Kadın & $18(\% 40,9)$ & $24(\% 52,1)$ & $p=0,064$ \\
\hline Erkek & $26(\% 59,1)$ & $22(\% 48,9)$ & $p=0,058$ \\
\hline Toplam & $44(\% 100)$ & $46(\% 100)$ & \\
\hline Yaş (ortalama ) (SD) & $26,84 \pm 8,16$ & $27,02 \pm 8,56$ & $\mathrm{p}=0,878$ \\
\hline \multicolumn{4}{|l|}{ Semptomlar } \\
\hline Ăğrı & $37(\% 84,0)$ & $41(\% 89,1)$ & $\mathrm{p}=0,682$ \\
\hline Kanama & $31(\% 70,4)$ & $34(\% 73,9)$ & $\mathrm{p}=0,436$ \\
\hline Kaşıntı & $9(20,4)$ & $11(\% 23,9)$ & $\mathrm{p}=0,169$ \\
\hline \multicolumn{4}{|l|}{ Komplikasyon } \\
\hline Ăğrı & 23 & $* * * *$ & \\
\hline Hematom & 0 & $2(\% 4,3)$ & $\mathrm{p}=0,096$ \\
\hline Apse & 0 & 0 & \\
\hline Gaz inkontinası (geçici) & 0 & $4(\% 8,6)$ & $p=0,041$ \\
\hline Gayta inkontinansı & 0 & 0 & \\
\hline \multicolumn{4}{|l|}{ 4. hafta muayanesi } \\
\hline Fissür var & $10(\% 22,7)$ & $4(\% 8,6)$ & $p=0,024$ \\
\hline Fissür yok & $34(\% 77,3)$ & $42(\% 91,4)$ & $p=0,048$ \\
\hline \multicolumn{4}{|l|}{ Enjeksiyon tekrarı } \\
\hline 2. uygulama & $6(\% 13,6)$ & $3(\% 6,5)$ & $p=0,038$ \\
\hline 3. uygulama & $4(\% 9,0)$ & $1(\% 2,1)$ & $\mathrm{p}=\mathbf{0 , 0 1 0}$ \\
\hline Yetersiz iyileşme & $3(\% 6,8)$ & $2(\% 4,3)$ & $\mathrm{p}=0,096$ \\
\hline Nüks & $3(\% 6,8)$ & $2(\% 4,3)$ & $\mathrm{p}=0,410$ \\
\hline Etkinlik \% & $38(\% 86.3)$ & $42(\% 91.3)$ & $\mathrm{p}=0,076$ \\
\hline
\end{tabular}

istekleri üzerine sfinkterotomi operasyonu ile tedavi edilirken diğer 4 hastada yeniden Botulinum enjeksiyonu yapıld. $\mathrm{Bu} 4$ hastanın sonraki kontrollerinde tamamen iyileşme izlendi. Bir yıllık kontrolde ise 2 hastada nüks anal fissür tespit edildi. Bu grupta 41 hastada işlem sonrası yaklaşık 3-4 gün süren perianal ağrı yakınması oldu. 2 hastada hematom geliști. Hematomlar kendiliğinden organize olarak iyileşti. Bu grupta 4 hastada gayta inkontinansı olmadan gaz inkontinansı izlendi. Yaklaşık 4-5 günlerde inkontinans şikâyetleri geçti. Apse ve gayta inkontinansı izlenmedi.

Birinci hafta kontrollerinde hastaların hiç birisinde rektal tuşede ağrı, dışkılamada herhangi bir sorun görülmedi. Tüm hastalar normal hayatlarına döndüklerini bildirdi (Tablo $1)$. 


\section{Tartışma ve Sonuç}

Son zamanlarda anal manometrinin yaygin kullanımı ile sfinkterotomiye bağlı inkontinans ve sfinkter konturunu azaltan cerrahi uygulamalar hastaların büyük bir bölümünde endişeye kaynağıdır (1). Bunun sonucu olarak cerrahi tedaviye isteksiz olan hastalarda bahsedilen inkontinans riski başka yol tedavi arayışlarını gündeme getirmiştir. Ayrıca cerrahi sonrası oluşan sfinkter inkontinansı cerrahlarda medikolegal endişelere yol açmaktadır $(1,2)$.

Anal sfinkter basıncını geri dönüşümlü olarak azaltan bazı nörotoksinler hakkında da pek çok araştırma yapılmıştır (1-8). Botulinum toksinin etkisi cerrahi sfinkterotomiye göre daha hafif kalmakta ve istenilen iyileşme sağlanabilmektedir. Yapılan birçok yayında internal sfinktere 3 faklı noktadan farklı dozlarda (15 IU- 150 IU) enjeksiyonlar tanımlanmıştır (3). Bizde bu çalışmada hastanemizde uygulanan 2 farklı dozun etkinliğini karşılaştırdık. Diğer pek çok çalışmadaki semptomlar ile bulgularımız benzerlik göstermekteydi ve her iki gruptaki en sık yakınma (Grup I de \%84, Grup II de\%89,1) defekasyon sonrası ağrı yakınması idi. Kanama ise (Grup I de \%70,4, Grup II de 73,9) yine sik izlenen yakınmaydı. Yine her iki grupta yaklaşık \%10 oranında anal kaşıntı (pruritis) şikâyeti mevcuttu.

Botulinum toksini herhangi bir anesteziye gerek olmadan kolayca yapıldı. Hastalardaki anal sfinkter gevşemesi kadın hastalarda 2. gün erkek hastalarda ise 3. gün başladı. Ağrı kesici ilk gün rutin sonrasında ise hastanın isteği üzerine lüzum halinde uygulandı. İşlem sonrası perianal ağrı şikâyeti Grup II'de \%89,1 gibi yüksek bir oranda Grup I'de ise \%52,2 oranında gelişti. İki grup arasındaki fark istatiksel olarak da anlamlı idi $(p=0,001)$. Yüksek doz uygulama sonrası daha çok ağriya neden oldu. Grup I'de hiçbir hastada hematom gelişmezken Grup II'de \%4,3 hastada hematom gelişti ve tedavisiz kendiliğinden düzelme oldu.
İki grup arasında istatiksel anlamlı farklılık saptanmadi $(p=0,096)$. Bu oranlar diğer yayınlarla ki hematom görülme oranları ile uyumludur (3). Gaz ve gayta inkontinansı bazı serilerde $\%$ 0-32 oranlarında verilmiş olup bu uygulamanın en korkulan komplikasyonudur. Ancak bu işlem sonrası gelişen inkontinans yaklaşık 6 ay içerisinde iyileşerek sfinkter normal fonksiyonuna dönecektir. Sfinkterotomide meydana gelen inkontinansin geri dönüşlü olmadığı hatırlanırsa bu oranlara rağmen Botulinum toksinin kullanımı daha güvenlidir. Bizim çalışmamızda Grup I'de hiçbir hastada inkontinans vakasına rastlamazken Grup II'de \%8,6 hastada 4-5 günde geçen izole gaz inkontinansı gelişti. $\mathrm{Bu}$ grupta da gayta inkontinansı izlenmedi. İki grup arasında gaz inkontinansı açısından bakıldığında istatiksel olarak anlamlı fark izlendi $(\mathrm{p}=0,041)$. Yüksek doz uygulama daha fazla gaz inkontinansina sebep oldu.

$\mathrm{Bu}$ tedavi yönteminin en büyük eksiliklerinden birisi de yetersiz iyileşmedir. Yeterli iyileşme sağlanamayan olgularda tekrarlayan enjeksiyonlar veya başka tedavi seçenekleri denenmektedir. Botulinum toksini uygulamasında maliyeti artıran en önemli faktör mükerrer enjeksiyon gereksinimidir. Çünkü her terapide yeni bir flakon kullanılır. Ayrıca bu hasta açısından yeniden ağrı, iş gücü kayb1 ve demoralizasyon anlamına gelmektedir. Bazı yayınlar tekrarlayan enjeksiyonu savunsa da maliyet ve hasta psikolojisi açısından biz daha az sayıda enjeksiyonun daha verimli olduğunu düşünmekteyiz. Çalışmamızda Grup I'de \%13,6 hastada, Grup II'de \%6,5 2 enjeksiyona gerek duyuldu ve bu iki grup arasında istatiksel olarak anlamlı fark mevcuttu $(\mathrm{p}=0,038)$. Yüksek doz yapılanlarda 2 . enjeksiyon gereksinimi azalmaktadır. 3. enjeksiyon gereksinimine bakıldığında Grup I'de $\% 9$, Grup II'de \%2,1 hastada uyguland1 ve aradaki fark istatistiksel olarak anlamlıydı $(p=0,010)$. Yine yüksek doz grubunda 3 . doz uygulama gereksiniminin azaldığı görüldü. 
Ancak bazen tekrarlayan enjeksiyonlar da yetersiz kalır. Çalışmamızda Grup I'de \%6,8, Grup II'de \%4,3 olguda yeterli iyileşme sağlanamadı ve bu hastalar sfinkterotomi ile tedavi edildi. İki grup arasında anlamlı istatiksel fark izlenmedi $(p=0,096)$.

Nüks hangi yöntem kullanılırsa kullanılsın hala önemli bir sorun olmaya devam etmektedir. Yayınlarda nüks oranları \%0-56 arasında verilmiștir (11-16). Çalıșmamızda 1 yıllık takip sonrası nüks oranları Grup I'de \%6,8, Grup II'de \% 4,3 olarak bulunmuştur. Yüksek doz gurubunda daha az nüks görülse de iki grup arasında istatiksel olarak anlamlı fark yoktu $(\mathrm{p}=0,310)$.

Etkinlik açısından değerlendirildiğinde Botulinum uygulamasının etkinliği \%38-96 gibi geniş bir oranda verilmiştir. Bu oran uygulanan merkezin deneyimi toksinin soğuk zincir kurallarına uyulmadan transportu gibi birçok nedene bağlı açıklanabilir. Çalışmamızda Grup I'de \%86,3 Grup II'de \%91,3 olarak bulundu. İki grup arasında istatiksel açıdan anlamlı bir fark yoktu $(p=0,076)$.

Tüm bu sonuçlar göz önüne alındığında yüksek doz (90 IU) Botulinum toksini uygulaması daha yüksek ağrı ve gaz inkontinansına neden olsa da daha yüksek iyileșme oranı daha az sayıda enjeksiyon uygulaması gerektirmesi nedeniyle tercih edilebilir bir tedavi yöntemidir.

\section{Kaynaklar}

1. Hazar H. Anal Fissure and High Dose Botulinum Toxin: A Pilot Study of 11 Patients. Kolon Rektum Hast Derg (TKRCD) 2013;23(1):24-30.

2. Dinç T, Ege B, Karslı MF, Faruk Coşkun F. Comparison of botox and lateral internal sphincterotomy treatment outcomes in chronic anal fissures. Dicle Medical Journale 2014;41 (1):133-7.

3. Bobkiewicz A, Francuzik W, Krokowicz L, Studniarek A, Ledwosiński W, Paszkowski J, et al. Botulinum Toxin Injection for Treatment of Chronic Anal Fissure: Is There Any DoseDependent Efficiency? A Meta-Analysis World J Surg. 2016;40(12):3064-3072.

4. Shao WJ, Li GC, Zhang ZK. Systematic review and meta-analysis of randomized controlled trials comparing botulinum toxin injection with lateral internal sphincterotomy for chronic anal fissure. Int J Colorectal Dis. 2009;24(9):995-1000.

5. Dat A, Chin M, Skinner S, Farmer C, Wale R, Carne $\mathrm{P}$ et al. Botulinum toxin therapy for chronic anal fissures: where are we at currently? ANZ J Surg. 2015;30.doi:10.1111/ ans.13329. [Epub ahead of print]

6. Scholz T, Hetzer FH, Dindo D, Demartines N, Clavien PA, Hahnloser D. Long-term follow-up after combined fissurectomy and Botox injection for chronic anal fissures. Int $\mathrm{J}$ Colorectal Dis.2007;22(9):1077-81.

7. Bibi S, Zutshi M, Gurland B, Hull T. Is Botox for anal pain an effective treatment option? Postgrad Med. 2016 Jan;128(1):41-5.

8. Piccinni G, Poli E, Angrisano A, Sciusco A, Testini M. Botox for chronic anal fissure: is it useful? A clinical experience with mid-term followup. Acta Biomed. 2009;80(3):238-42.

9. Mehrotra S. Beyond Beauty: Botulinum Toxin Use in Anal Fissure. Med J Armed Forces India. 2009;65(3):213-5.

10. Brisinda G, Vanella S, Crocco A, Maria G. Type A botulinum toxin treatment for chronic anal fissure. Int J Colorectal Dis. 2012;27(11):1543-5.

11. Wald A, Bharucha AE, Cosman BC, Whitehead WE. ACG clinical guideline: Management of benign anorectal disorders. Am J Gastroenterol 2014;109:1141-57.

12. Glover PH, Tang SJ, Whatley JZ, et al. Highdose circumferential chemodenervation of the internal anal sphincter: A new treatment modality for uncomplicated chronic anal fissure: A retrospective cohort study (with video). Int J Surg 2015;23:1-4.

13. Yiannakopoulou E. Botulinum toxin and anal fissure: Efficacy and safety systematic review. Int J Colorectal Dis 2012;27:1-9.

14. Sajid MS, Hunte S, Hippolyte S, Kiri VA, Maringe C, Baig MK. Comparison of surgical vs chemical sphincterotomy using botulinum toxin for the treatment of chronic anal fissure: A metaanalysis. Colorectal Dis 2008;10:547-52.

15. Witte ME, Klaase JM. Botulinum toxin A injection in ISDN ointment-resistant chronic anal fissures. Dig Surg 2007; 24:197-201.

16. Nasr M, Ezzat H, Elsebae M. Botulinum toxin injection versus lateral internal sphincterotomy in the treatment of chronic anal fissure: A randomized controlled trial. World J Surg 2010; 34: 2730-4. 